\title{
Role of the ubiquitin/proteasome system on ACTH turnover in rat corticotropes
}

\author{
Antonella Sesta ${ }^{1}$ Maria Francesca Cassarino ${ }^{1}$ - Francesco Cavagnini ${ }^{1}$ Francesca Pecori Giraldi $\circledast^{1,2}$
}

Received: 16 November 2017 / Accepted: 26 February 2018 / Published online: 13 March 2018

(C) The Author(s) 2018. This article is an open access publication

\begin{abstract}
Purpose A large number of studies has investigated proopiomelanocortin processing in anterior pituitary corticotropes but little is known on proopiomelanocortin/ACTH degradation within these cells. The ubiquitin-proteasome system is an intracellular protein degradation pathway which has garnered considerable interest in recent times, given its role in maintenance of protein homeostasis. Aim of the present study was to evaluate the role of the ubiquitin-proteasome system in proopiomelanocortin/ACTH turnover in pituitary corticotropes.

Methods Rat anterior pituitary primary cultures were treated with $0.01-100 \mathrm{nM}$ MG132, a proteasome inhibitor, or 0.1-100 nM K48R, an inhibitor of polyubiquitylation, for 4 and $24 \mathrm{~h}$ and ACTH concentrations in medium and cell lysates estimated by immunometric assay. Co-immunoprecipitation for ubiquitin and ACTH was carried out to establish ubiquitintagged protein products.

Results Inhibition of proteasome-mediated degradation with MG132 lead to an increase in ACTH concentrations, both as regards secretion and cell content. Likewise, inhibition of polyubiquitylation was associated with increased ACTH secretion and cell content. Ubiquitin/ACTH co-immunoprecipitation revealed that proopiomelanocortin was a target of ubiquitylation. Conclusions We provide the first evidence that the ubiquitin-proteasome system is involved in proopiomelanocortin/ACTH degradation in corticotropes. Indeed, proopiomelanocortin is a target of ubiquitylation and modulation of ubiquitinproteasome system affects ACTH turnover. This study shows that regulation of ACTH proteolytic degradation may represent a means to control ACTH secretion.
\end{abstract}

Keywords Proopiomelanocortin $\cdot$ ACTH $\cdot$ Ubiquitin-proteasome $\cdot$ Ubiquitylation

\section{Introduction}

ACTH is a major component of the hypothalamo-pituitary adrenal axis and, thus, pivotal to survival. ACTH is synthesized in anterior pituitary corticotropes upon processing of its precursor, proopiomelanocortin (POMC) and indeed $P O M C$ null mice [1] or patients carrying a mutation in the

Electronic supplementary material The online version of this article (https://doi.org/10.1007/s12020-018-1573-9) contains supplementary material, which is available to authorized users.

Francesca Pecori Giraldi

fpg@auxologico.it

1 Neuroendocrinology Research Laboratory, Istituto Auxologico Italiano IRCCS, Cusano Milanino (Milan), Milan, Italy

2 Department of Clinical Sciences and Community Health, University of Milan, Milan, Italy
POMC gene [2] have severe hypocortisolism. POMC, a 241-aminoacid prohormone, is synthesized in the rough endoplasmic reticulum, sorted in the Golgi complex and processed to 39-aminoacid ACTH in secretory granules by prohormone convertase 1/3 (PC1) and cathepsin L [3-5]. ACTH then awaits in mature granules of the regulated secretory pathway until secretion is triggered by specific stimuli [6].

On the other hand, intracellular proteolysis also contributes to active peptide concentrations [7,8] and eukaryotic cells possess two main proteolytic systems, the vacuolar-lysosomal and the ubiquitin-proteasome system (UPS). The latter, in particular, is deputized to removal of damaged or misfolded proteins, i.e., protein quality control, degradation of short half-life peptides $[9,10]$ and regulation of intracellular levels of de novo synthesized proteins [11, 12]. Interest in the UPS proteolytic system increased considerably in recent years as impairment in UPS function has been implicated a variety of degenerative diseases, 
including Parkinson and Alzheimer, as well as neoplasias, e.g., breast cancer [7, 13-16]. Degradation of proteins by the ubiquitin-proteasome system is accomplished in two steps: mono/polyubiquitylation of the target protein followed by proteolytic degradation of the ubiquitylated protein by the $26 \mathrm{~S}$ proteasome macromolecular complex [9]. Ubiquitin is attached to its substrate through an enzymatic cascade, comprising an ubiquitin-activating enzyme (E1), an ubiquitin conjugase (E2) and an ubiquitin ligase (E3). These enzymes conjugate the substrate onto ubiquitin via its lysine residues, i.e., ubiquitylation, and, given that ubiquitin contains 7 lysine residues, consecutive rounds of ubiquitylation can result in the formation of long and diverse ubiquitin chains $[9,17]$. The tagged protein is then anchored to the $26 \mathrm{~S}$ proteasome and degraded and free, reusable ubiquitin released.

Aim of the present study was to evaluate the role of ubiquitin-proteasome system on ACTH turnover in pituitary corticotropes. Our study identified POMC as a target of ubiquitylation and showed that inhibitors of ubiquitylation and of the ubiquitin-proteasome system increased ACTH cell content, as well as secretion. It follows, therefore, that ubiquitylation is directly involved in regulation of intracellular ACTH homeostasis.

\section{Materials and methods}

\section{Rat anterior pituitary primary cultures}

Anterior pituitaries were obtained by dissection from adult male Sprague-Dawley rats (rattus norvegicus, Charles River Laboratories, Calco, Italy) maintained in light-dark cycle and temperature-controlled rooms with free access to laboratory chow and tap water. Animals were treated according to the National Institutes of Health, Office of Animal Care and Use recommendations and authorization from the University of Milan Animal Care offices was obtained prior to the study. Pituitaries were established in culture using our usual protocol $[18,19]$. Briefly, anterior pituitaries were excised, dispersed with trypsin, cell dispersions pooled and cells plated at $4-5 \times 10,000$ cell/well density in 12-well polystyrene plates (Corning Inc., Corning NY, USA). Primary cultures were attached in Dulbecco's modified Eagle's medium (DMEM), containing glucose and L-glutamine supplemented with $10 \%$ fetal bovine serum and antibiotics and maintained at $5 \% \mathrm{CO}_{2}, 37^{\circ} \mathrm{C}$ for $3-5$ days.

\section{Treatments}

Rat anterior pituitary primary cultures were incubated in serum-free DMEM $+0.1 \%$ bovine serum albumin (BSA) containing 0.01-100 nM carbobenzoxy-L-leucyl-L-leucyl-Lleucinal MG132, a peptide aldehyde which selectively inhibits chymotrypsin-like proteolysis and the ubiquitin-proteasome pathway $[12,20]$, or $0.1-100 \mathrm{nM}$ mutant ubiquitin K48R, an inhibitor of polyubiquitylation [21]. Co-treatments with $5 \mu \mathrm{M}$ cycloheximide, an inhibitor of protein synthesis and translational elongation, and $0.01-10 \mathrm{nM}$ MG132 were also performed. Control wells were treated with DMEM and $0.1 \%$ BSA alone and each treatment was performed in quadruplicate. After 4 and $24 \mathrm{~h}$, medium was collected and cell content extracted. Parallel assessments for cell viability were performed with trypan blue staining [22]. All reagents were obtained from Sigma-Aldrich, St. Louis MO, USA and stock solutions dissolved according to the manufacturer's instructions, i.e., MG312 in DMSO, K48R in sterile water. Experiments were repeated at least thrice.

\section{Co-immunoprecipitation and Western blotting}

Total protein was extracted from control wells by RIPA Lysis buffer ( $25 \mathrm{mM}$ Tris- $\mathrm{HCl} \mathrm{pH}$ 7.6, $150 \mathrm{mM} \mathrm{NaCl}, 1 \%$ NP-40, $1 \%$ sodium deoxycholate, $0.1 \%$ SDS; Thermo Scientific, Rockford IL, USA) supplemented with protease and phosphatase inhibitor cocktail (Sigma Aldrich, St. Louis MO, USA). Protein concentration was measured using Bradford assay (BioRad, Hercules CA, USA). For coimmunoprecipitation experiments, cell lysates $(150 \mu \mathrm{g})$ were incubated at $4{ }^{\circ} \mathrm{C}$ overnight with anti-ubiquitin rabbit polyclonal primary antibody (1:2000 dilution; Abcam, Cambridge, UK) and non immune IgG (i.e., non specific control). Protein complexes were captured on Protein A/G PLUSagarose (Santa Cruz Biotechnology Inc. Dallas TX, USA). Ubiquitin-precipitated pituitary primary culture cell extracts were separated on SDS-PAGE using a $4-12 \%$ gradient (NuPage gel in Tris-glicine, Life Technologies, Carlsbad CA, USA) under denaturing conditions. Proteins bands were transferred to Hybond ECL nitrocellulose membrane (GE Healthcare, Little Chalfont, UK) and the membrane blocked with 5\% non-fat milk, incubated with anti-ACTH rabbit polyclonal primary antibody raised against the entire 1-39 sequence (1:1000 dilution; Abcam, Cambridge, UK) followed by incubation with horseradish peroxidase-conjugated secondary goat polyclonal anti-rabbit antibody (1:10000 dilution; Invitrogen, Camarillo CA, USA). Blots were developed using enhanced chemiluminescence technique. Bioinformatic prediction of ubiquitylation sites on rat POMC protein sequence (GenBank Accession \# AAH58443) was perfomed at www.ubpred.org.

\section{Assays}

ACTH in cell extracts and media was measured by immunoradiometric assay (Diasorin S.p.A. Saluggia, Italy). 
This sandwich assay uses two antibodies, one specific to ACTH 1-17 and the other to ACTH 26-39, thus measures intact ACTH 1-39. No interference with POMC is expected given assay methodology. Intraassay coefficient of variation is $7.9 \%$, and assay sensitivity $1.2 \mathrm{pg} / \mathrm{ml}$. Responses were normalized to percent of control secretion (unstimulated secretion $=100 \%$ ). Prolactin in cell extracts and media was measured by immunoradiometric assay (Institute of Isotopes, Budapest, Hungary). Intraassay coefficient of variation is $3.2 \%$, and assay sensitivity $0.07 \mathrm{ng} / \mathrm{tube}$.

\section{Statistical analysis}

Statistical comparisons were performed using ANOVA followed by Fisher's PLSD post-hoc test. Statistical significance accepted at $p<0.05$. Data are described as mean \pm S.E.M.

\section{Results}

First, we sought to determine targets of ubiquitylation by ubiquitin/ACTH co-immunoprecipitation. Western blotting on ubiquitin-precipitated cell extracts showed that only the POMC precursor was ubiquitylated as no band corresponding to ACTH was detected in ubiquitin-tagged precipitates (Fig. 1). As expected, ubiquitylated POMC and prePOMC presented higher molecular weight compared to native POMC by approx. $8 \mathrm{kDa}$ corresponding to ubiquitin moieties. Both isoforms of POMC, i.e., non-glycosylated and glycosylated fragments, appeared to be targets of ubiquitylation as was the 267 -aminoacid prePOMC precursor. The search for canonical ubiquitylation sites on the rat POMC sequence revealed 4 potential lysine residues at 76 , 122, 163, and 184.

We then evaluated the effects of MG132, an inhibitor of degradation by proteasome, on ACTH levels and observed an increase in ACTH concentrations in medium and cell content. The increase in ACTH secretion was evident both $4 \mathrm{~h}$ and $24 \mathrm{~h}$ (ANOVA $F=2.446, p<0.05$ and $F=3.857$, $p<0.01$, respectively), up to twice as high with $0.01 \mathrm{nM}$ MG132 at $4 \mathrm{~h}$ (Fig. 2). The increase in cell content was significant at both timepoints $(\mathrm{F}=5.031, p<0.005$ and $F$ $=3.261, p<0.05$, for $4 \mathrm{~h}$ and 24 , respectively) up to $50 \%$ of unchallenged wells (Fig. 2). Specificity of MG132 proteasome inhibition on POMC/ACTH was assessed by measuring prolactin, as prolactin secretion is known not to be affected by proteasome inhibitors.[23] Indeed, prolactin levels in cell extracts and medium did not change following MG132 treatment (medium: $110.3 \pm 6.81 \%$ control; extract: $94.5 \pm 9.69 \%$ control after $24 \mathrm{~h}$ incubation, N.S.). No changes in cell viability were observed during MG132
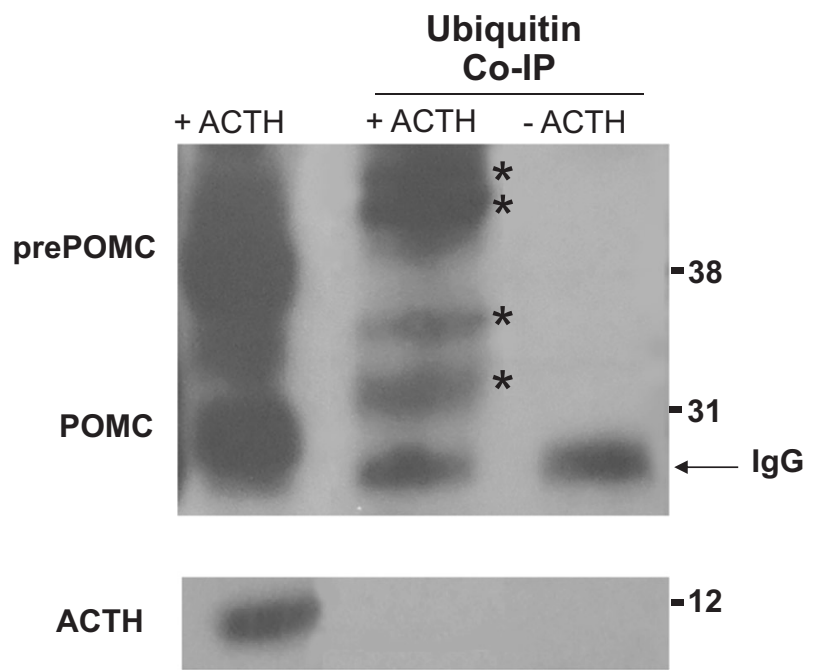

Fig. 1 Ubiquitin/ACTH co-immunoprecipitation in rat anterior pituitary primary cell extracts. Left lane shows input blotted for ACTH: prePOMC $(\sim 39 \mathrm{kDa})$, POMC $(\sim 29 \mathrm{kDa})$ and ACTH $(\sim 6 \mathrm{kDa})$ are visible. Middle lane shows ubiquitin-tagged ACTH-blotted fragments: Asterisk (*) identfies two bands for ubiquitylated POMC (i.e., $\sim 32 \mathrm{kDa}$ non-glycosylated and $\sim 37 \mathrm{kDa}$ glycosylated POMC) and prePOMC ubiquitylated fragments ( $\sim 45 \mathrm{kDa}$ and over). No band was observed at the expected size for ubiquitylated ACTH. Right lane shows ubiquitin immunoprecipitation without ACTH blotting: arrow identifies IgG light chains $(\sim 23 \mathrm{KDa})$ visible in both middle and right lanes

incubation (Supplementary Table 1) thus observed effects are not due to toxicity.

Incubation with K48R, an inhibitor of polyubiquitylation, also led to a significant increase in ACTH medium concentrations after $24 \mathrm{~h}(F=5.504, p<0.05$; Fig. 3). Likewise, ACTH cell content was increased during $24 \mathrm{~h}$ incubation with $\mathrm{K} 48 \mathrm{R}(F=3.550, p<0.05$; Fig. 3). No significant effect was observed after $4 \mathrm{~h}$ K48R incubation in either medium $(F=0.401$, N.S. $)$ or cell content $(F=1.498$, N.S.) Lastly, no changes in cell viability were observed during incubation with K48R, (Supplementary Table 1) again attesting to lack of toxicity at the doses tested.

In order to establish whether the proteasome acts upon newly synthetized ACTH, we performed co-incubation experiments with $5 \mu \mathrm{M}$ cycloheximide. ACTH medium concentrations were decreased by some $70 \%$ after $24 \mathrm{~h}$ incubation with cycloheximide ( $F=278.18, p<0.001$; Fig. $4)$; as in the previously-described experiments without cycloheximide, MG132 co-incubation brought about an increase in ACTH concentrations $(F=8.827, p<0.01$, Fig. 4) indicating that proteasome inhibition acts in absence of de novo synthetized ACTH. Inhibition by cyclohexamide was less evident at $4 \mathrm{~h}(F=6.907, p<0.05)$ and the counteracting effects of MG132 did not reach significance $(F=0.979$, N.S.; Fig. 4). No effect of cycloheximide incubation on cell content was observed at either timepoint (4h: $F=1.293$, N.S.; 24 h: $F=0.210$, N.S.) thus no 

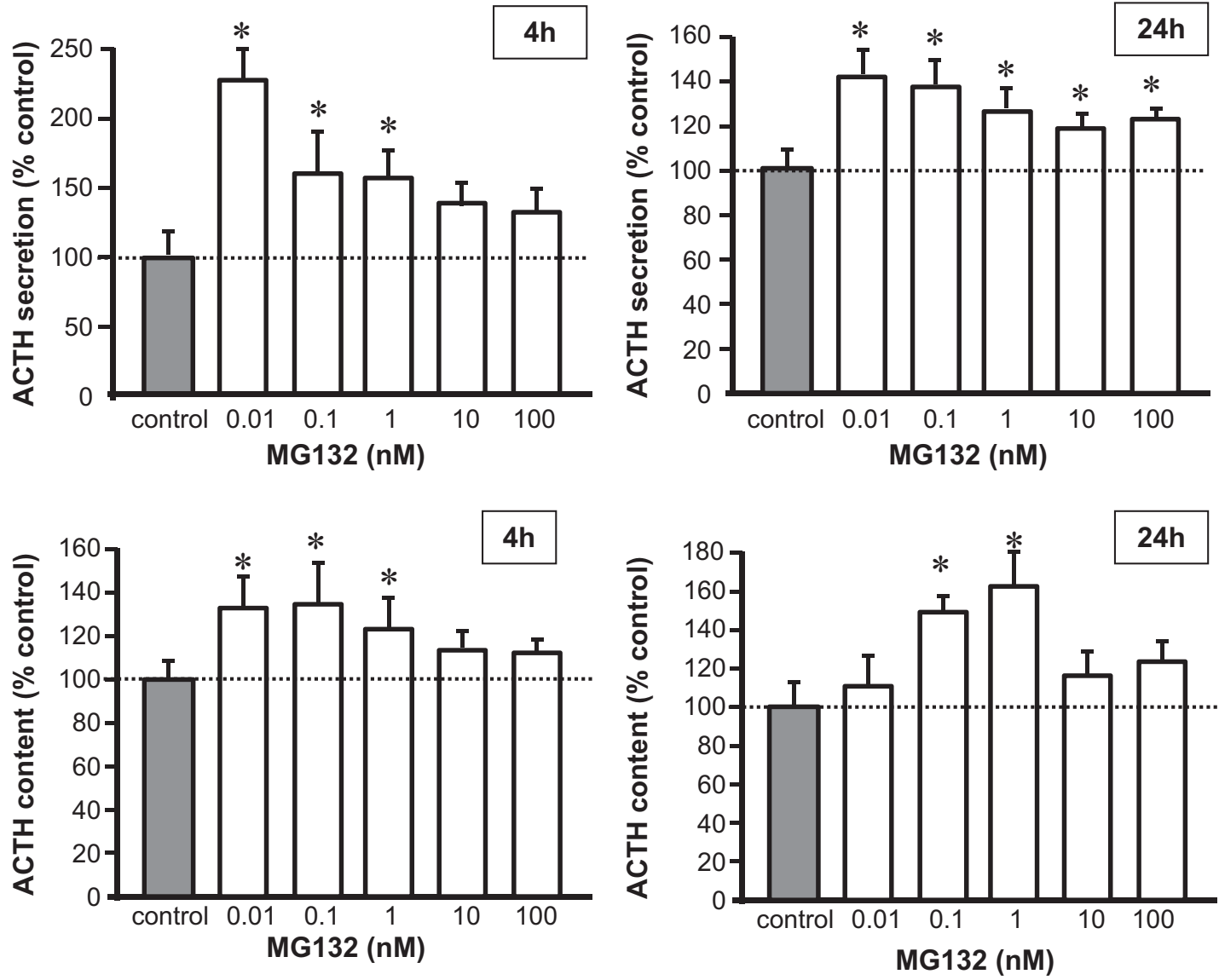

Fig. 2 ACTH concentrations in medium and cell content in rat anterior pituitary primary cell cultures treated with $0.01-100 \mathrm{nM}$ MG132 for $4 \mathrm{~h}$ and $24 \mathrm{~h}$ (white bars). Each treatment was carried out at least thrice

on quadruplicate $4-5 \times 10,000$ cells/well. Dashed line represent unchallenged wells set at $100 \%$ (control; gray bar). Asterisk (*) denotes $p<0.05$ vs. control as assessed by Fisher's PLSD post-hoc test

counteracting effect of MG132 could be observed ( $4 \mathrm{~h}: F=$ 0.318 , N.S.; 24 h: $F=0.455$, N.S.).

\section{Discussion}

Our study provides the first demonstration that the POMC peptide is degraded by the ubiquitin-proteasome system (UPS) in corticotrope cells and that modulation of the UPS system directly affects ACTH turnover and secretion. Indeed, while there is a considerable body of studies on POMC processing to ACTH and other POMC-derived peptides, such as $\beta$-lipotropin, $\alpha$ - and $\beta$-melanocyte-stimulating hormones, little is known on degradation of POMC or its derived peptides.

The ubiquitin-proteasome system is a highly selective cytosolic protein degradation mechanism [9] whose main function is removal of abnormal proteins, which may prove toxic if accumulated, and of rapidly acting regulatory proteins, whose short half-lives have evolved to facilitate regulation of their activity $[10,17,24]$. Thus, it participates in wide array of cellular processes including cell signaling, cell

cycle progression, differentiation and apoptosis [9]. Derangement of UPS has been implicated in neurodegenerative disorders such as Parkinson's disease, [13] Alzheimer's disease [25], in nephrotic disease [26] and, importantly, neoplasia [15]. In fact, proteasome inhibitors are a relatively new target-treatment class for cancer [12] and some compounds, e.g., bortezomib, have already been approved for use in hematologic malignancies and offer promise for solid tumors [14, 16].

In physiological conditions, the ubiquitin-proteasome system together with the lysosomal apparatus subserve protein degradation to maintain appropriate intracellular protein stores, the so-called "proteostasis" [17]. The importance of proteases in maintaining overall intracellular ACTH metabolism has previously been shown for cysteine and aspartyl proteases [27]. In our study, we demonstrate for the first time that the UPS is involved in corticotrope POMC/ACTH turnover.

We observed a clear increase in ACTH concentrations in intracellular stores and incubation medium during incubation with MG132, an UPS-protease inhibitor. Similar effects were observed with the mutant ubiquitin K48R, an inhibitor 


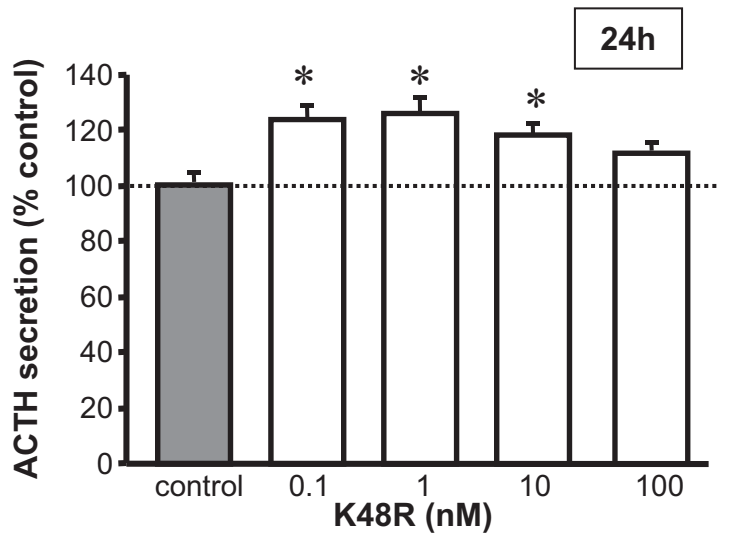

Fig. 3 ACTH concentrations in medium and cell content in rat anterior pituitary primary cell cultures treated with $0.1-100 \mathrm{nM} \mathrm{K} 48 \mathrm{R}$ for $4 \mathrm{~h}$ and $24 \mathrm{~h}$ (white bars). Each treatment was carried out at least thrice on

of polyubiquitylation, which proves that attachment of ubiquitin chains is required for POMC/ACTH degradation. In order to identify targets of ubiquitylation, we performed ubiquitin/ACTH co-immunoprecipitation studies and can report that proteins in the molecular weight range of POMC and prePOMC were ubiquitylated whereas ACTH itself did not appear a target of ubiquitylation. Of note, the POMC peptide contains four lysine residues -canonical ubiquitin target sites- and an abundance of cysteines, serines and threonines which may represent alternative ubiquitylation sites [28].

Given that POMC is transported from the endoplasmic reticulum to the transGolgi network [3, 6], it is likely that POMC is subject to endoplasmic reticulum-associated degradation (ERAD), a process that allows proteins to be back-transported out of the endoplasmic reticulum to the cytoplasm and thus degraded by cytoplasmic UPS [29, 30]. ERAD was initially discovered as a mechanism for removal of misfolded proteins from the endoplasmic reticulum but was subsequently also demonstrated to occur also for regulated proteins $[11,31]$. POMC would therefore be targeted by ubiquitin ligases located in endoplasmic reticulum membrane and delivered to the cytoplasm via the retrotranslocation complex [31]. Any change in ACTH, which is formed downstream to the endoplasmic reticulum, would thus be secondary to ubiquitylation of its prohormone prior to $\mathrm{PC} 1$ cleavage $[3,6]$. On the other hand, ubiquitylation has recently been demonstrated to promote also lysosomal sorting [32], thus ubiquitylated POMC could also be directed towards lysosomal degradation. In fact, protein substrate sorting to either proteasomes or lysosomes depends on ubiquitylated lysines, as well as length and type of polyubiquitin chain branching [33]. Given that MG132 and K48R clearly increased ACTH concentrations, ubiquitin-mediated lysosomal degradation may come into play as an additional proteolytic process.

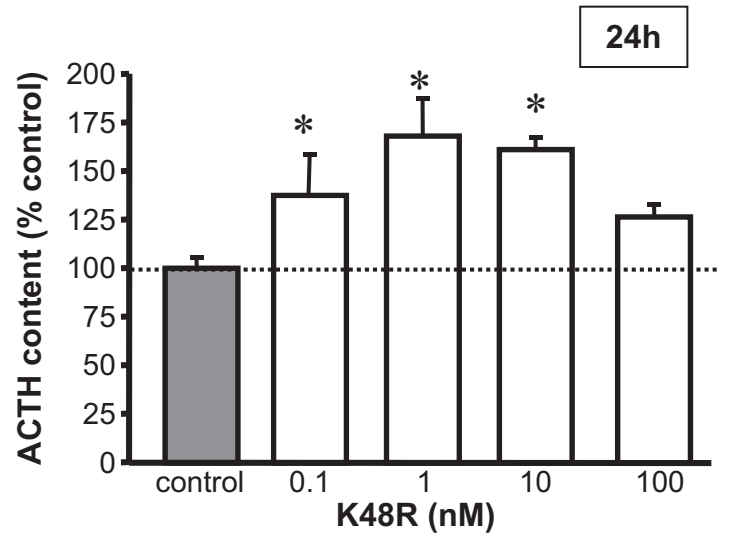

quadruplicate 4-5 × 10,000 cells/well. Dashed line represent unchallenged wells set at $100 \%$ (control; grey bar). Asterisk (*) denotes $p<$ 0.05 vs. control as assessed by Fisher's PLSD post-hoc test

An increase in ACTH secretion was observed already after $4 \mathrm{~h}$ incubation with MG132, suggesting reduced degradation of the ready releasable pool of POMC/ACTH [6]. Indeed, the effect of MG132 was evident also during cyclohexamide blockade, indicating that UPS-proteases do not require newly synthesized ACTH, but act upon protein moieties already present within the cell. In this context, although co-immunoprecipitation experiments proved that POMC is a direct target for ubiquitylation, additional factors may come into play given the complexity of POMC synthesis and processing [3, 6]. Inhibition of ubiquitylation may interfere with proteolytic degradation of any factor involved in POMC-to-ACTH processing, e.g., PC1, cathepsin $\mathrm{L}[4,6]$, thus leading to increased activity of these enzymes. Of note, MG132 has been shown to inhibit proteolysis of mutated PC1 [34] but whether the convertase is target of ubiquitin-mediated proteasomal degradation in physiological conditions remains to be seen. In this context, it is worth noting that the effect of both agents on ACTH homeostasis was more pronounced in the pico- and low nanomolar range and less in the high nanomolar range. This suggests that MG132 and K48R act upon several intracellular ubiquitylation targets -possibly with contrasting functions- which ultimately affect ACTH synthesis/secretion.

Our findings on the role of UPS in POMC/ACTH turnover are of particular interest given the recent reports on gain-offunction mutations in the thiol protease deubiquitinase USP8 gene in patients with $\mathrm{ACTH}$-secreting pituitary adenomas, i.e., Cushing's disease [35-37]. Deubiquitinases are enzymes which remove ubiquitin moieties from a given substrate thus steering proteins tagged for proteolysis away from their intended fate [17]. Mutations in the USP8 14-3-3 binding motif lead to increased catalytic activity $[35,36]$ and USP 8 mutants result in increased deubiquitination of ligand-activated epidermal growth factor (EGF) receptor [35, 36], a factor involved in tumoral corticotrope pathophysiology [38, 39]. Ultimately, USP8 


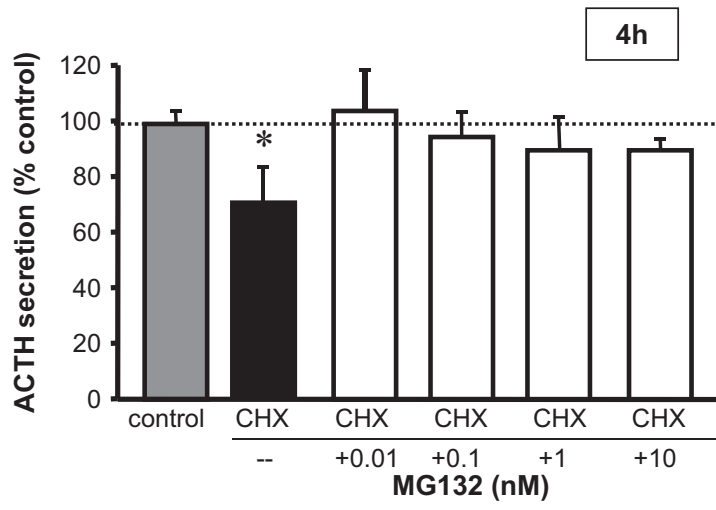

Fig. 4 ACTH concentrations in medium in rat anterior pituitary primary cell cultures treated with $5 \mu \mathrm{m}$ cycloheximide (CHX; black bar) and $0.01-10 \mathrm{nM}$ MG132 for 4 and $24 \mathrm{~h}$ (white bars). Each treatment was carried out at least thrice on quadruplicate $4-5 \times 10,000$ cells/well.

mutants lead to inhibition of EGF signaling downregulation and increased Pomc expression and ACTH secretion [35, 36]. In addition to this effect of tumoral corticotrope secretory activity, UPS also appear involved in tumoral corticotrope proliferation as silencing of cullin $4 \mathrm{~A}$, a core subunit of $\mathrm{E} 3$ ubiquitin ligase, led to decreased proliferation of AtT-20 cells [40].

In conclusion, our study provides evidence that the POMC peptide is degraded by the ubiquitin-proteasome pathway and that inhibition of ubiquitylation increases ACTH concentrations. These results show that modulation of the UPS affects ACTH turnover in corticotrope cells and pave the way to novel avenues of research in both normal and neoplastic ACTH-secreting cells.

Funding This work was supported by a non-restricted grant from Novartis Farma SpA, Origgio (Varese), Italy.

\section{Compliance with ethical standards}

Conflict of interest The authors declare that they have no conflict of interest.

Ethical approval This article does not contain any studies with human participants performed by any of the authors. All applicable international, national, and/or institutional guidelines for the care and use of animals were followed.

Open Access This article is distributed under the terms of the Creative Commons Attribution 4.0 International License (http://crea tivecommons.org/licenses/by/4.0/), which permits unrestricted use, distribution, and reproduction in any medium, provided you give appropriate credit to the original author(s) and the source, provide a link to the Creative Commons license, and indicate if changes were made.

\section{References}

1. L. Yaswen, N. Diehl, M.B. Brennan, U. Hochgeschwender, Obesity in the mouse model of pro-opiomelanocortin deficiency responds to peripheral melanocortin. Nat. Med. 5, 1066-1070 (1999)

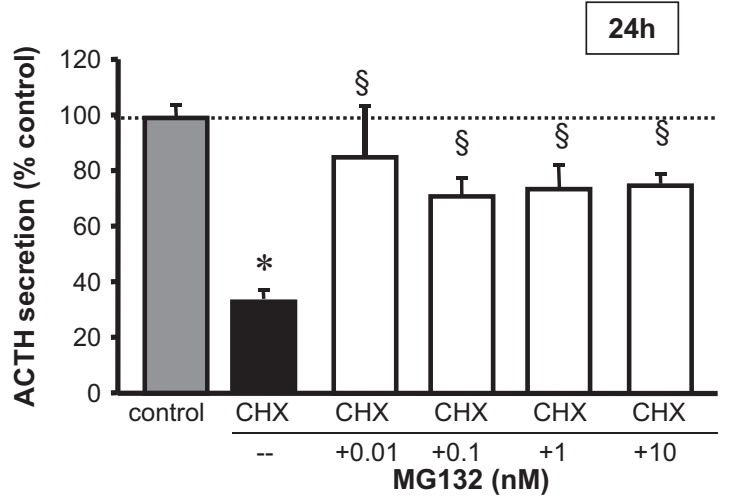

Dashed line represent unchallenged wells set at $100 \%$ (control; grey bar). Asterisk $(*)$ denotes $p<0.05$ vs. control; ${ }^{\S} p<0.05$ vs. cycloheximide as assessed by Fisher's PLSD post-hoc test

2. H. Krude, H. Biebermann, W. Luck, R. Horn, G. Brabant, A. Grüters, Severe early-onset obesity, adrenal insufficiency and red hair pigmentation caused by POMC mutations in humans. Nat. Genet. 19, 155-157 (1998)

3. S. Tanaka, Comparative aspects of intracellular proteolytic processing of peptide hormone precursors: studies on proopiomelanocortin processing. Zool. Sci. 20, 1183-1198 (2003)

4. L. Funkelstein, T. Toneff, C. Mosier, S.R. Hwang, F. Beuschlein, U.D. Lichtenauer, T. Reinheckel, C. Peters, V. Hook, Major role of cathepsin $\mathrm{L}$ for producing the peptide hormones $\mathrm{ACTH}$, betaendorphin, and alpha-MSH, illustrated by protease gene knockout and expression. J. Biol. Chem. 283, 35652-35659 (2008)

5. M. Chrétien, M. Mbikay, From the prohormone theory to proopiomelanocortin and to proprotein convertases (PCSK1 to PCSK9). J. Mol. Endocrinol. 56, T49-T62 (2016)

6. N.X. Cawley, Z. Li, Y.P. Loh, Biosynthesis, trafficking, and secretion of pro-opiomelanocortin-derived peptides. J. Mol. Endocrinol. 56, T77-T97 (2016)

7. H. Hoelen, A. Zaldumbide, W.F. van Leeuwen, E.C. Torfs, M.A. Engelse, C. Hassan, R.J. Lebbink, E.J. de Koning, M.E. Resssing, A.H. de Ru, P.A. van Veelen, R.C. Hoeben, B.O. Roep, E.J. Wiertz, Proteasomal degradation of proinsulin requires derlin-2, HRD1 and p97. PloS ONE 10, e0128206 (2015)

8. V.D. Moi, E. Bacsy, G. Gaal, G. Rappay, Lysosomal enzyme activities in hypo- and hypersecretory anterior pituitary cells. A combined immunocytochemical and enzyme cytochemical study. Histochemistry 81, 79-85 (1984)

9. A. Ciechanover, Intracellular protein degradation: from a vague idea, through the lysosome and the ubiquitin-proteasome system, and onto human diseases and drug targeting (Nobel lecture). Angew. Chem. Int. Ed. 44, 5944-5967 (2005)

10. M. Shen, S. Schmitt, D. Buac, Q.P. Dou, Targeting the ubiquitinproteasome system for cancer therapy. Expert. Opin. Ther. Targets 17, 1091-1108 (2013)

11. S.H. Lecker, A.L. Goldberg, W.E. Mitch, Protein degradation by the ubiquitin-proteasome pathway in normal and disease states. J. Am. Soc. Nephrol. 17, 1807-1819 (2006)

12. D. Chen, Q.P. Dou, The ubiquitin-proteasome system as a prospective molecular target for cancer treatment and prevention. Curr. Protein Pept. Sci. 11, 459-470 (2010)

13. R. Betarbet, T.B. Sherer, J.T. Greenamyre, Ubiquitin-proteasome system and Parkinson's diseases. Exp. Neurol. 191, S17-S27 (2005)

14. R.Z. Orlowski, E.C. Dees, The role of the ubiquitinationproteasome pathway in breast cancer: applying drugs that affect 
the ubiquitin-proteasome pathway to the therapy of breast cancer. Breast Cancer Res. 5, 1-7 (2003)

15. F. Bassermann, R. Eichner, M. Pagano, The ubiquitin proteasome system - implications for cell cycle control and the targeted treatment of cancer. Biochim. Biophys. Acta 1843, 150-162 (2014)

16. D.E. Johnson, The ubiquitin-proteasome system: opportunities for therapeutic intervention in solid tumors. Endocr. Relat. Cancer 22, T1-T17 (2015).

17. Z.M. Eletr, K.D. Wilkinson, Regulation of proteolysis by human deubiquitinating enzymes. Biochim. Biophys. Acta 1843, 114-128 (2014)

18. F. Pecori Giraldi, F. Cavagnini, Corticotropin-releasing hormone is produced by rat corticotropes and modulates ACTH secretion in a paracrine/autocrine fashion. J. Clin. Invest. 101, 2478-2484 (1998)

19. F. Pecori Giraldi, S. Pesce, P. Maroni, L. Pagliardini, G. Lasio, M. Losa, F. Cavagnini, Inhibitory effect of preproTRH(178-199) on ACTH secretion by human corticotrope tumours. J. Neuroendocrinol. 22, 294-300 (2010)

20. D.H. Lee, A.L. Goldberg, Selective inhibitors of the proteasomedependent and vacuolar pathways of protein degradation in saccharomyces cerevisiae. J. Biol. Chem. 271, 27280-27284 (1996)

21. V. Chau, J.W. Tobias, A. Bachmair, D. Marriott, D.J. Ecker, D.K. Gonda, A. Varshavsky, A multiubiquitin chain is confined to specific lysine in a targeted short-lived protein. Science 243, 1576-1583 (1989)

22. K.S. Louis, A.C. Siegel, Cell viability analysis using trypan blue: manual and automated methods. Methods Mol. Biol. 740, 7-12 (2011)

23. R. Yu, S.G. Ren, S. Melmed, Proteasome inhibitors induce apoptosis in growth hormone- and prolactin-secreting rat pituitary tumor cells. J. Endocrinol. 174, 379-386 (2002)

24. D.H. Lee, A.L. Goldberg, Proteasome inhibitors: valuable new tools for cell biologists. Trends Cell Biol. 8, 397-403 (1998)

25. H.C. Tai, A. Serrano-Pozo, T. Hashimoto, M.P. Frosch, T.L. Spires-Jones, B.T. Hyman, The synaptic accumulation of hyperphosphorylated tau oligomers in Alzheimer disease is associated with dysfunction of the ubiquitin-proteasome system. Am. J. Pathol. 181, 1426-1435 (2012)

26. M. Beeken, M.T. Lindenmeyer, S.M. Blattner, V. Radon, J. Oh, T.N. Meyer, D. Hildebrand, H. Schluter, A.T. Reinicke, J.H. Knop, A. Vivekanandan-Giri, S. Munster, M. Sachs, T. Wiech, S. Pennathur, C.D. Cohen, M. Kretzler, R.A. Stahl, C. MeyerSchwesinger, Alterations in the ubiquitin proteasome system in persistent but not reversible proteinuric diseases. J. Am. Soc. Nephrol. 25, 2511-2525 (2014)

27. C. Sei, T. Toneff, W. Aaron, V.Y.H. Hook, Regulation of ACTH levels in anterior pituitary cells during stimulated secretion: evidence for aspartyl and cysteine proteases in the cellular metabolism of ACTH. Peptides 24, 717-725 (2003)

28. Y. Kravtsova-Ivantsiv, T. Sommer, A. Ciechanover, The lysine48based polyubiquitin chain proteasomal signal: not a single child anymore. Angew. Chem. Int. Ed. 52, 192-198 (2013)
29. B. Meusser, C. Hirsch, E. Jarosch, T. Sommer, ERAD: the long road to destruction. Nat. Cell Biol. 7, 766-772 (2005)

30. R.Y. Hampton, T. Sommer, Finding the will and the way of ERAD substrate retrotranslocation. Curr. Opin. Cell Biol. 24, 460-466 (2012)

31. I. Amm, T. Sommer, D.H. Wolf, Protein quality control and elimination of protein waste: the role of the ubiquitin-proteasome system. Biochim. Biophys. Acta 1843, 182-196 (2014)

32. M.J. Clague, S. Urbe, Ubiquitin: same molecule, different degradation pathways. Cell 143, 682-685 (2010)

33. L. Qiao, J. Zhang, Inhibition of lysosomal functions reduces proteasomal activity. Neurosci. Lett. 456, 15-19 (2009)

34. P. Stijnen, B. Brouwers, E. Dirkx, B. Ramos-Molina, L. Van Lommel, F. Schuit, L. Thorrez, J. Declercq, J.W. Creemers, Endoplasmic reticulum-associated degradation of the mouse PC1/ 3-N222D hypomorph and human PCSK1 mutations contributes to obesity. Int. J. Obes. 40, 973-981 (2016)

35. M. Reincke, S. Sbiera, A. Hayakawa, M. Theodoropoulou, A. Osswald, F. Beuschlein, T. Meitinger, E. Mizuno-Yamasaki, K. Kawaguchi, Y. Saeki, K. Tanaka, T. Wieland, E. Graf, W. Saeger, C.L. Ronchi, B. Allolio, M. Buchfelder, T.M. Strom, M. Fassnacht, M. Komada, Mutations in the deubiquitinase gene USP8 cause Cushing's disease. Nat. Genet. 47, 31-38 (2015)

36. Z.Y. Ma, Z.J. Song, J.H. Chen, Y.F. Wang, S.Q. Li, L.F. Zhou, Y. Mao, Y.M. Li, R.G. Hu, Z.Y. Zhang, H.Y. Ye, M. Shen, X.F. Shou, Z.Q. Li, H. Peng, Q.Z. Wang, D.Z. Zhou, X.L. Qin, J. Ji, J. Zheng, H. Chen, Y. Wang, D.Y. Geng, W.J. Tang, C.W. Fu, Z.F. Shi, Y.C. Zhang, Z. Ye, W.Q. He, Q.L. Zhang, Q.S. Tang, R. Xie, J.W. Shen, Z.J. Wen, J. Zhou, T. Wang, S. Huang, H.J. Qiu, N.D. Qiao, Y. Zhang, L. Pan, W.M. Bao, Y.C. Liu, C.X. Huang, Y.Y. Shi, Y. Zhao, Recurrent gain-of-function USP8mutations in Cushing's disease. Cell Res. 25, 306-317 (2015)

37. L.G. Perez-Rivas, M. Theodoropoulou, F. Ferrau, C. Nusser, K. Kawaguchi, C.A. Stratakis, F.F. Rueda, L.E. Wildemberg, G. Assie, R. Beschorner, C. Dimopoulou, M. Buchfelder, V. Popovic, C.M. Berr, M. Toth, A.I. Ardisasmita, J. Honegger, J. Bertherat, M.R. Gadelha, F. Beuschlein, G.K. Stalla, M. Komada, M. Korbonits, M. Reincke, The gene of the ubiquitin-specific protease 8 is frequently mutated in adenomas causing Cushing's disease. J. Clin. Endocrinol. Metab. 100, E997-E1004 (2015)

38. M. Theodoropoulou, T. Arzberger, Y. Gruebler, M.L. JaffrainRea, J. Schlegel, L. Schaaf, E. Petrangeli, M. Losa, G.K. Stalla, U. Pagotto, Expression of epidermal growth factor receptor in neoplastic pituitary cells: evidence for a role in corticotropinoma cells. J. Endocrinol. 183, 385-394 (2004)

39. H. Fukuoka, O. Cooper, A. Ben-Shlomo, A.N. Mamelak, S.G. Ren, D. Bruyette, S. Melmed, EGFR as a therapeutic target for human, canine, and mouse ACTH-secreting pituitary adenomas. J. Clin. Invest. 121, 4712-4721 (2011)

40. Y. Xu, Y. Wang, G. Ma, Q. Wang, G. Wei, CUL4A is overexpressed in human pituitary adenomas and regulates pituitary tumor cell proliferation. J. NeuroOncol. 116, 625-632 (2014) 